\title{
Zum Tod von C. Wolfgang Müller
}

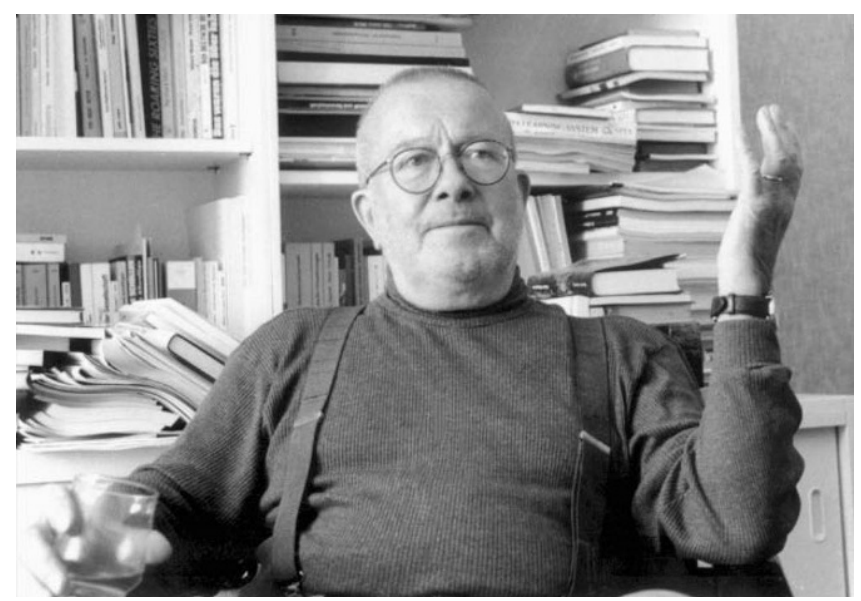

Ein langes Leben ist zu Ende gegangen. Am 21. April ist C. Wolfgang Müller im 93. Lebensjahr gestorben. Bis in seine letzten Lebenstage war er - mehr als sechs Jahrzehnte - als Praktiker und Theoretiker der Sozialen Arbeit aktiv. Er verstand sich als Sozialpädagoge, vor allem aber als Gruppenpädagoge. Dieses Engagement rührte aus seinen frühen Erfahrungen in der Jugendbewegung. Während eines Studienaufenthaltes in den USA begeisterte er sich für die von deutsch-jüdischen Emigrant_innen dort entwickelte Gruppenpädagogik und Gruppendynamik. Auch sein späteres Engagement für die Gemeinwesenarbeit resultierte aus seinen Erfahrungen in den USA.

Im West-Berlin der 1950er und 60er-Jahre konnte er seine Fähigkeiten und Kenntnisse in einem offenen Jugendclub und als Leiter einer Ausbildungsstätte für Jugendarbeit (Haus Am Rupenhorn) umsetzen. 1964 gehörte er zu den Autoren des Klassikers „Was ist Jugendarbeit? “, der einer ganzen Generation in den Jugendverbänden und in den „Häusern der offenen Tür“ wesentliche Anstöße für ihr Denken und Handeln gab.

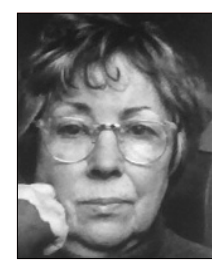

\section{Sabine Hering}

Sozialpädagogik, Gender und Wohlfahrtsgeschichte,Universität Siegen, Siegen, Deutschland

*1947. Potsdam.

hering@kulturareale.de

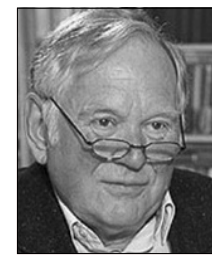

\section{Manfred Kappeler}

Sozialpädagogik,TU Berlin, Berlin, Deutschland

*1940. Berlin. Sozialpädagoge, Kinder- und Jugendlichenpsychotherapeut.

drkappeler@posteo.de
Als im Kontext der Bildungsreform und der 68er-Bewegung die Einrichtung von universitären Diplomstudiengängen für Erziehungswissenschaften beschlossen wurde, konzipierte und gründete $\mathrm{C}$. Wolfgang Müller an der Pädagogischen Hochschule Berlin den Diplomstudiengang Sozialpädagogik mit der spezifischen Verbindung von Theorie und Praxis. Als der Studiengang nach der Auflösung der Pädagogischen Hochschule an der TU Berlin weitergeführt wurde, war C. Wolfgang Müller bis zu seiner Emeritierung im Jahr 1996 der spiritus rector des auch nach seiner Auflösung legendären Instituts.

In den 1980er-Jahren wurde C. Wolfgang Müller zum Vorreiter der bisher brachliegenden Aufarbeitung der Wohlfahrtsgeschichte - erinnert sei hier vor allem an das bis heute immer wieder aufgelegte Werk „Wie Helfen zum Beruf wurde“. Vor allem für diese Pionierarbeit wurde ihm 2010 an der Universität Siegen die Ehrendoktorwürde verliehen. $\mathrm{Zu}$ seinen Ehren gibt es seit 2018 in Siegen die „C. Wolfgang Müller Lectures“.

In seinen letzten Lebensjahren hat er u. a. mit seinen ebenso informativen wie unterhaltsamen „Briefen aus Berlin" in Sozial Extra an seine journalistische Arbeit in der Berliner Spiegel-Redaktion zu Beginn der1950erJahre angeknüpft - bis zu seinem Ende hellwach, kritisch, stilistisch brillant. Der in dieser Ausgabe veröffentliche Brief „In der Reinhardtstraße. Wo sich Lobbyisten und Politiker in Berlin treffen " ist leider sein letzter.

C. Wolfgang Müller war ein begnadeter Lehrer und Ermutiger, ein auch in schwierigsten politischen Auseinandersetzungen solidarischer Kollege, ein unermüdlicher Förderer und Unterstützer des Nachwuchses in Forschung, Lehre und Praxis - und für viele Frauen und Männer ein wunderbarer Freund.

\section{Sabine Hering und Manfred Kappeler}

Eingegangen. 22. April 2021

Angenommen. 22. April 2021 